\title{
Chapter 21 \\ Co-design as Infrastructuring with Attention to Power: Building Collective Capacity for Equitable Teaching and Learning Through Design-Based Implementation Research
}

\author{
William R. Penuel
}

The chapters in this volume explore different ways that co-design of curriculum can make learning more relevant to teachers and students, support teacher learning, and promote the sustainability of particular innovations. Many of the chapters conclude that in fact, there is great potential for co-design to support each of these aims. Co-design, for example, can promote teacher ownership over the curriculum, including when reform goals that guide development are set by policy makers who are far from the classroom (Westbroek, de Vries, Walraven, Handelzalts, \& McKenney, this volume). Co-design can facilitate "curriculum renewal" among inservice teachers - that is, a transformation in teachers' goals for students and pedagogical approaches. For pre-service teachers, co-design can support integration of technology into teaching (Agyei \& Kafyulilo, this volume; Alayyar \& Fisser, this volume). Further, teachers can continue to learn from the implementation process (Huizinga, Nieveen, \& Handelzalts, this volume). Finally, there is some evidence presented in this volume that co-design facilitates sustainability by creating processes for ongoing curriculum renewal.

But the chapters in this volume also explore limitations or boundary conditions under which co-design can produce these positive outcomes. For one, the organizational conditions matter. Teachers need time not just to develop curriculum, but also to learn the skills of curriculum design and to implement and evaluate it using a cycle of iterative testing and revision (Albashiry, this volume; Handelzalts, Nieveen, \& Van den Akker, this volume). And since most curriculum design projects require coordination among actors at different levels of systems and within organization, systems of formal and informal communication to ensure coherence are needed

W. R. Penuel $(\bowtie)$

School of Education and Institute of Cognitive Science, University of Colorado Boulder,

Boulder, CO, USA

e-mail: William.Penuel@colorado.edu 
(Handelzalts, et al., this volume). A well-facilitated design process helps teachers keep from floundering and take into considerations related to how particular curriculum structures and pedagogies can best support student learning (Handelzalts et al., this volume). Further, careful attention to cultural and political dimensions of design processes and implementation-related to national, regional, and schoollevel processes - is required for co-design to succeed (Agyei \& Kafyulilo, this volume; Gervedink Nijhuis, this volume).

These conditions are difficult to create for all design teams, and even when they are in place, implementation of co-designed materials still varies (Huizinga, Nieveen, \& Handelzaltz, this volume). And in a number of instances cited in the chapters, co-design resulted more in a reproduction of existing pedagogies, rather than their transformation. These challenges raise the important question, Is there any way to make co-design more reliable as a strategy for promoting transformational change in educational systems?

I argue in this chapter that we can make co-design more reliable, but that it requires a shift in how we think about the purposes of co-design and also its relationship to the organizational contexts in which co-design takes place. To summarize this argument briefly, co-design must be embedded within long-term research-practice partnerships in which external partners (e.g., researchers) and teachers in joint work to evaluate and iterate upon both the processes and products of design. Second, design must focus on the goal of promoting collective capacity and be motivated by a concern for democratizing the process of innovation and professional renewal. Third, to accomplish this goal, design must focus both on curriculum and on redesigning the infrastructures that support the effective implementation of curricula. I illustrate what this approach looks like by drawing on the experiences of a research-practice partnership in Colorado (USA).

\section{The Importance of Research-Practice Partnerships for Implementing and Sustaining Change in Educational Systems}

A typical cooperative engagement between an educational organization and a team of researchers is short-term, and the goals are largely defined by the educational organization, the researchers, or some external policy that both partners are implementing. Many of the projects described in the volume-especially those involving international cooperation-focused on supporting the goals of educational organizations. By contrast, in the United States, research and development projects involving co-design have often been driven by researchers' goals (e.g., Penuel, Roschelle, \& Shechtman, 2007). Many of the examples from the Netherlands in this volume represented occasions where co-design served the goals of policymakers, or where as Westbroek and colleagues put it, co-design was a bottom-up strategy for a topdown innovation. When the initiative or grant ends, the cooperation often ends, and 
it is difficult to sustain innovations that have been developed and tested without the ongoing support and involvement of external partners (Fishman, Penuel, Hegedus, \& Roschelle, 2011).

In a research-practice partnership, goals for research and development are collaboratively defined, and the commitment to working together is both long-term and open-ended. Research-practice partnerships are intentionally organized collaborations focused on investigating problems of practice and solutions for improving outcomes in educational systems (Coburn \& Penuel, 2016). The phrase "intentionally organized" here connotes some formal arrangement and routine ways of interacting with one another-such as through co-design of curriculum materials-that help partners arrive at deeper, shared understanding of problems and to design, test, and iterate on solutions to those problems. And while the focus is always on improving practice, partnerships can and do develop knowledge and tools that are useful for other researchers and partnerships (Henrick, Cobb, Penuel, Jackson, \& Clark, 2017). Further, the understanding of the problems to be addressed is a negotiated understanding - one that reflects the concerns and goals of different stakeholders in the partnership (Penuel, Coburn, \& Gallagher, 2013).

It is partners' commitment to following the "contours of a problem" (Donovan, 2013) wherever the research and development process may lead that makes them particularly valuable for improving the reliability of outcomes of co-design. Research-practice partnerships do not just develop and test innovations; they document and take action to reduce barriers to implementation that make innovations less successful (Penuel \& Gallagher, 2017). Research evidence is always formativeeven when findings are ultimately published in academic journals. And partnerships develop new lines of work continuously that arise from problems of implementation, as well as those that arise from emerging priorities, concerns, and interests of the partnership. When successful, partnerships add value to both the research and practice organizations, and they lead not just to renewal of educational resources like curriculum, but to professional renewal- that is, to the sense among participants that they are doing meaningful work that energizes them (Frumin, 2018).

\section{Reframing the Aims of Co-design}

Educational organizations such as schools and districts, as well as educational ecosystems comprised of formal and informal organizations in a community, are first and foremost concerned with improving outcomes for learners. While leaders in these organizations recognize the central importance of curriculum materials, interventions, and practices in helping accomplish these outcomes, they view these as tools or means to accomplishing these larger objectives. Moreover, any given practice or curriculum will be one among many that organizations deploy to improve outcomes. As such, a key task of leaders is to support coordination among strategies, so that they yield coherent guidance to educators about what and how to teach (Forman, Stosich, \& Bocala, 2017; Jackson \& Cobb, 2013; Linn, Kali, Davis, \& 
Horwitz, 2008). Without such coordination, educators are left to make sense of conflicting guidance on their own, often leading to unintended interpretations of policy (Coburn, 2001), disappointing and inequitable student outcomes (Newmann, Smith, Allensworth, \& Bryk, 2001), and teacher burnout (Bryk, Gomez, Grunow, \& LeMahieu, 2015).

In a partnership — where concerns related to practice are centered-the focus on outcomes necessitates a shift in how we think about the goals of co-design. It is not sufficient to ask how to sustain a particular innovation, and nor is it adequate to think about how co-design can support many individual teachers' learning. Rather, we have to consider how the process and products of co-design build capacity in the partnership for bringing about educational change (Penuel, 2017). This is a shift away from viewing curriculum as a cause of student learning or support for individual teacher change, as is typical within education research. Further, it invites us to ask questions about what capacities are needed and how co-design fits within a broad range of strategies for building capacity. Finally, in framing the target of capacity-building as the partnership itself - rather than the educational organization-we position ourselves as researchers not in a position of knowing what is best for teachers and education leaders, but as co-learners who must grow with and alongside our partners.

For many partnerships - including our own - equity is a central concern, and foregrounding equity necessitates a further refinement of the goals of co-design. Where some scholars foreground the value of co-design in promoting the usability and sustainability of particular innovations (e.g., Blumenfeld, Fishman, Krajcik, Marx, \& Soloway, 2000), we foreground the goal of democratizing innovation, that is, to expand authority in design to a multiplicity of voices in the struggle to define the aims and means of education (Björgvinsson, Ehn, \& Hillgren, 2010). In the context of our research practice-partnership, the goal of democratizing innovation means that we are continuously seeking to expand opportunities to participate in shaping the goals and strategies of reform to include a wide range of stakeholders who are not typically at the table during the design process, such as parents, students, and family members. We also mean foregrounding the concerns of these stakeholders in the products we create and taking into consideration how the design process must be structured to include and heed their voices (Penuel, 2014). Co-design, in such situations, inevitably entails some repair of inequitable social relations, not just the building of a new curriculum or application (Booker \& Goldman, 2016; Ishimaru \& Takahashi, 2017).

This latter goal of democratizing innovation puts us squarely within the traditions of participatory design that are well-developed in Scandinavia (Björgvinsson, Ehn, \& Hillgren, 2012a, 2012b) and are emerging within the learning sciences community (Bang \& Vossoughi, 2016; DiSalvo, Yip, Bonsignore, \& DiSalvo, 2017). This is important, because it gives us a language for describing what we are doing when we co-design (e.g., Hillgren, Seravalli, \& Emilson, 2011) and a set of values that link us to commitments to social and economic democracy (Ehn, 1992). It also makes demands of us to attend carefully to questions of "Who designs?" and to how 
power and privilege can undermine efforts to transform inequity through co-design (Esmonde \& Booker, 2017; Mendoza, Kirshner, \& Gutiérrez, 2018).

\section{Co-design as Infrastructuring with Attention to Power}

One of the terms from participatory design we find useful in our partnership to characterize the work we do is infrastructuring. The term's origins trace partly back to the insights of Leigh Star (2010) related to why some workplace technologies are not reliably taken up, even if users find them in principle both useful and usable: users do "not know how to make a reliable working infrastructure out of it" (p. 610, emphasis added). By that Leigh meant that users could not integrate it into their work in such a way that it met their goals while also becoming invisible to them as a distinct tool, like most good infrastructure is. To say that a goal of co-design is to infrastructure is to assert that a goal must be to create innovations that fit seamlessly within their work context and support users in making a reliable working infrastructure of those innovations. "Fitting seamlessly" in an educational context rife with inequities of resources and opportunities to learn doesn't mean "works under routine conditions of schools", however, as is the goal of researchers seeking to demonstrate educational effectiveness of particular innovations (cf., Institute of Education Sciences \& National Science Foundation, 2013). Rather, infrastructuring efforts demand that we also re-design educational infrastructures that influence implementation to be more equitable (Penuel, 2015). When we "design across levels" in this way, we are engaged in a special kind of design research my colleagues and I call Design-Based Implementation Research (DBIR; Fishman, Penuel, Allen, Cheng, \& Sabelli, 2013), so named because we are concerned with developing knowledge, tools, and practices related to equitable implementation of innovations and the capacity of partnerships to improve outcomes through inclusive research and development processes.

What are some of the elements and processes that make up educational infrastructures that we target in DBIR projects? Some elements identified in policy research include:

- Standards for student learning,

- Curricular materials,

- Student assessments,

- Teacher professional development,

- Instructional techniques and routines (e.g., for promoting productive talk in classrooms),

- Building and district level policies (e.g., regarding posting of standards, submission of lesson plans that follow a particular format),

- School schedules that allocate instructional time for different subjects,

- Roles and positions focused on instructional support (e.g., coaches), 
- Organizational routines, such as grade level meetings, where instruction is a focus, and

- Personnel evaluation systems, including the forms of evidence that contribute to assessment of a teacher's performance (Cohen, Peurach, Glazer, Gates, \& Goldin, 2013; Hopkins \& Spillane, 2015; Peurach \& Neumerski, 2015; Smith \& O'Day, 1991; Spillane, Parise, \& Sherer, 2011; Woulfin, 2015).

Some of the processes that bring these different components into being and into relation to one another are leaders' "sensegiving" (Gioia \& Chittipeddi, 1991) activities meant to help teachers navigate the multitude of conflicting messages that teachers face every day about what and how to teach (Coburn \& Woulfin, 2012), routines such as grade-level and department meetings (Coburn, 2001; Spillane et al., 2011), professional development activities intended to help teachers make a working infrastructure of district-led or external initiatives (Johnson, Severance, Penuel, \& Leary, 2016). Schools and districts sometimes even convene groups and re-organize systems that are focused specifically on increasing the coherence of the existing infrastructure (Elmore \& Burney, 1997; Kirp, 2013).

All of these activities take place within hierarchical and interlocking systems, which have been described as "heterarchies" (Stephenson, 2009) because the networks that connect people and policies often span different levels. The policies and programs that make up a system reflect the past efforts of those with power to set direction for school districts, and rather than being replaced, infrastructures-like the decisions that led to their development in the first place- - tend to accrete (Power, 2015). Infrastructure reifies categories — of goals (e.g., "standards"), of strategies (e.g., "evidence-based practice"), and of persons (e.g., "students with disabilities") - in ways that structure social relations and that produce "residuals," that is, situations and even people who do not fit into the categories and that require organizational actors to confront (Bowker \& Star, 1999). Attending to power in infrastructuring requires a kind of analytic act of "inversion" to make visible infrastructures and reconstruct the history of their development, to name who benefited and who suffered from the use of particular categories, and to make transparent and more democratic processes for re-design of infrastructure (Bowker \& Star).

\section{Infrastructuring in the Inquiry Hub Research-Practice Partnership}

Below, I briefly describe two examples of how co-design has supported the goals of capacity building and democratizing innovation in the Inquiry Hub, an ongoing, 11-year old research-practice partnership between the University of Colorado Boulder and Denver Public Schools. The two activities involve more than just the university and district as partners. They also involve other universities and nonprofit research centers, as well as community organizations. I have chosen these examples, because the initial line of work that spawned these infrastructuring efforts was 
a curriculum co-design effort focused on developing and testing a year-long biology curriculum. Like some of the initiatives described here, co-design started out as a bottom-up strategy to achieve externally defined goals for learning - that is, a new set of standards for science called the Next Generation Science Standards (NGSS; NGSS Lead States, 2013). Over the course of 4 years of design research, we developed both materials and a set of routines for the co-design of problem- and projectbased units that are connected to students' interests. Details about the curriculum units and the collaborative design process used to develop and test them are presented elsewhere (Penuel et al., 2018; Severance, Penuel, Sumner, \& Leary, 2016). Here, I focus on other co-design efforts that emerged as necessary to support the implementation of the units.

\section{Co-design of Assessments of Student Learning}

From the very first iteration of our first unit on ecosystems, teachers raised concerns that the units we had designed together had too few opportunities for assessing student learning. At first, I was puzzled by this concern, because the units included many opportunities for students to express their thinking in small group and whole group discussion, as well as in writing. A final project plan for choosing a tree to plant in each participating classroom's schoolyard required students to show what they had learned about ecosystem dynamics. What more, we wondered, might teachers need?

As the co-design team comprised of teachers, researchers, and district leaders dug deeper, we discovered a number of issues related to assessment that we would need to address - both of students and of the teachers themselves. For example, the district had end-of-unit tests that were not well aligned to the new unit that teachers were required both to administer and score. In addition, early in our design process, the district initiated a new set of procedures and tools for teachers to use to document student growth in their classrooms, as part of their own evaluation, known in Denver elsewhere as Student Learning Objectives (Crouse, Gitomer, \& Joyce, 2016). What's more, teachers reported to us their principals each had different requirements for grades and grading; at least one was required to have assignments and grades posted to a learning management system that restricted the kinds of questions that teachers could ask to multiple-choice formats.

While it would be impossible for our small co-design team to tackle all of these challenges at once, we began a series of what participatory designers call "patchwork efforts" (Emilson, Hillgren, \& Seravalli, 2014) to support implementation. The unifying goal of these efforts was to a coherent guidance infrastructure for teachers, so that they could feel free to test out new curriculum that did not yet fit neatly within the layered infrastructure that already existed for them.

Though initially - to fit within the time constraints of district processes-members of the research team undertook these efforts ourselves, we realized we needed to create small co-design teams focused on building tools that could become part of 
the district's instructional guidance infrastructure. A particularly successful effort related to assessment was the development of a rubric that teachers could use to analyze student work products from the curriculum that they could include as part of a portfolio of evidence that their students had met their Student Learning Objectives. The effort was successful, because it demonstrated how by implementing a lesson and grading student work, teachers could produce evidence that would have legitimacy in the eyes of the district with respect to demonstrating their own effectiveness as teachers.

A longer-term effort has focused on building capacity district wide for the development of so-called "three-dimensional assessments," that is, assessments of student learning that measure students' integrated understanding of disciplinary core ideas, science and engineering practices, and crosscutting concepts. Such assessments are difficult to develop and quite distinct from typical multiple-choice tests (National Research Council, 2014; Pellegrino, 2013). Here, our team has undertaken a multi-pronged strategy, involving both direct writing of assessments that could be included on district tests and structured professional development for teacher teams that write these district tests. The long-term aim is to integrate multicomponent performance tasks into district tests that are written by teachers who have a deep understanding of how to develop such tasks. Though today many district tests do include such tasks, the effort to transform district tests is an ongoing patchwork effort.

Both of these efforts illustrate co-design as strategies for democratizing innovation and building collective capacity. Teachers were involved not just as co-designers of curriculum materials but as co-designers of components of district infrastructure related to assessment. In so doing, they gained a say in shaping the tools that supervisors at the school and district levels would use to evaluate teaching effectiveness. Through participation in professional development followed by design of assessments, they further contributed to the infrastructure, and the district gained a new capacity for writing assessment tasks that were better aligned to the new vision of science proficiency reflected in the Next Generation Science Standards.

\section{Co-designing with Youth to Develop more Inclusive Classroom Cultures}

One of the most persistent asymmetries in classrooms is the authority of teachers relative to students (Apple, 1982; Buzzelli \& Johnston, 2001; Oyler, 1995). Teachers have both the power to direct activity within the classroom and to establish what counts as knowledge that students must master (Gore, 1995). In science education, the second kind of authority is problematic for helping students develop an appreciation for the uncertainty of scientific knowledge and its development (Aguiar, Mortimer, \& Scott, 2010). Indeed, learning sciences research has underscored that productive disciplinary engagement requires students develop authority for 
constructing, developing, and critiquing knowledge claims in the classroom (Engle, 2012). Sharing authority among students and teachers for knowledge development can also further democratic ideals of dialogue and deliberation, through disciplinary learning (Michaels, O'Connor, \& Resnick, 2008).

In the early years of research on our new curriculum materials, we discovered many different ways that power and authority relations in classrooms served not only as an obstacle to curriculum implementation but also to teachers taking time to learn about their students' ideas, interests and experiences. We discovered this both through informal observations and through the use of a kind of "practical measure" (Yeager, Bryk, Muhich, Hausman, \& Morales, 2013) that captured student experiences in classrooms. This measure elicited students' perceptions of the coherence and relevance of a given day's lesson to them and to their communities. In studies of multiple classrooms where we used this measure, we found wide variation across classrooms in students' perceptions of coherence and relevance (Penuel, Van Horne, Severance, Quigley, \& Sumner, 2016). These were supported by observations in which we saw teachers engaged in a lot of "telling" students the science ideas within the curriculum, even though the curriculum afforded many different avenues to help students construct their own understandings through guided inquiry into natural phenomena.

As a co-design team comprised of select teachers, district leaders, and researchers, we decided that professional development in the curriculum was not sufficient to accomplish the shifts in authority needed or create classrooms where teachers attended closely to students' ideas and questions. We added to our partnership additional team members from Northwestern University (Reiser, Novak, \& McGill, 2017) and the Next Generation Exemplar System (Reiser, Michaels, et al., 2017) and shifted our efforts in the past year to designing professional development for teachers that focused on building an inclusive classroom culture of "figuring out the science ideas together," and we highlighted the kind of talk moves and formats (Michaels \& O'Connor, 2011) that could promote student sensemaking and deliberative dialogue among students and teachers about science ideas.

We realized, too, that to change classrooms to be places where students' ideas and questions had more of a say would require the direct involvement of students in our co-design efforts. Where we had not engaged students as co-designers in the past, we formed a new partnership with a community-based youth organization in Denver, Project Voyce, that works in partnership with schools to develop youth-led professional development related to creating respectful, inclusive classrooms. The work that a small co-design team comprised of students, teachers, researchers, and representatives from Project Voyce is now undertaking is the development of protocols that teachers and students in classrooms can follow to ensure that students' perceptions of the coherence and relevance of classroom activities cannot be predicted by their race, their gender, or their home language.

This particular infrastructuring effort represents our recent efforts to attend carefully to issues of power and authority between students and teachers. In this effort, we have kept the science context focal - mindful of the ways that scientific communities share (not always equitably) authority for developing knowledge claims 
and critiquing knowledge claims of others. And, we have extended our co-design practice so that students have more of a say in some of the classroom routines used with our curriculum - at least in those classrooms where teacher volunteers have begun to take up this work. As with the first infrastructuring effort described above, this effort is ongoing - as nearly every infrastructuring effort in a large system and within a research-practice partnership is - and does not reach every student in the district. We have a long way to go to accomplish our aims of democratizing innovation and building capacity.

\section{Making Co-design More Reliable: A Principled Approach}

From the outside - and certainly from a traditional linear model of research and development — our approach might seem reactive and unprincipled. But our partnership is guided by a set of principles that we follow as practitioners of Design-Based Implementation Research (DBIR; Fishman et al., 2013). These principles might also help the next generation of co-design projects become more reliable, in terms of their outcomes. Already, a number of the chapters illustrate these principles in action, even if not all together or in ways that are explicit within the chapters. I close with a description of the principles and an explanation of how infrastructuring efforts like our own can embody them.

Principle 1: Research is focused on addressing shared goals to address persistent problems of practice from multiple stakeholders' points of view. The emphasis on shared goals here highlights the central importance of working in partnershipnot just with educators, but all those who have a stake in a focal problem. In the infrastructuring efforts described above, we describe co-design that includes researchers, district leaders, teachers, youth, and community-based organization. In DBIR, the focus is on persistent problems-like inequity of opportunityrather than on problems that a single administrator or policy maker might decide must be addressed tomorrow. Persistent problems hint at systemic inequities and the operation of power in ways that can focus and sharpen DBIR projects. As is richly illustrated in a number of chapters in this volume, this principle can be embodied by study of the problems and the contexts where work will take place.

Principle 2: Commitment to collaborative, iterative design. Co-design is an essential feature of DBIR projects, and it is framed as a commitment that can yield not only more usable designs but also helps to realize the goal of democratizing innovation. Though sometimes we fail in this commitment in our own work when we engage in patchwork efforts to support implementation, we are reminded always that when we want to develop capacity as a partnership in a particular area, we need to establish a co-design team. This volume is a testament 
to the multitude of benefits that come from co-designing with teachers and nongovernmental organizations; even more is possible when we broaden who designs to encompass students and community members and parents (Bang, Medin, Washinawatok, \& Chapman, 2010; Barajas-López \& Ishimaru, in press).

Principle 3: Developing knowledge, tools, and practices related both to classroom learning and implementation. DBIR always has at least two layers of theory and is involved in design across levels or settings in educational settings. One layer of theory pertains to classroom (or out of school) learning, and this theory guides design for student or youth learning. Another layer guides our change efforts-it might be a theory of teacher learning such as guides many of the efforts described in this volume, or a theory of organizational change, as also guides some efforts presented here. In our own work, theories of productive disciplinary engagement support design of interventions to create inclusive classroom cultures, and theories related to the role that educational infrastructures play in informing teacher decision making guide precisely where we decide to spend time and effort. Our "reactivity" in addressing issues related to assessment, for example, is not so reactive as it is acting in ways that assume some regularities across educational infrastructure exist in how they influence teaching. Both the infrastructure and patterns of influence have become focal points of co-design; different ones will emerge as important if our partnership continues to evolve.

Principle 4: Building capacity for continuous change within a research-practice partnership. Capacity here is how we have described it in our efforts-as the collective capabilities of a group of co-designers to create, test, and refine designs using evidence from implementation. This principle emphasizes the continuous nature of these cycles, in ways that align with contemporary movements in education related to improvement science (Bryk et al., 2015). We emphasize this capacity as one of a partnership_rather than of a research or educational organization-because the commitment in partnerships is open-ended. Unlike the traditional research and development models where there is an expected "transfer of ownership," ownership is baked into the processes of partnership development and routines of co-design. And while partners must still work to build ownership among those who have not been involved in the design process, this challenge is a shared challenge taken on by the partnership.

I believe the application of these principles can guide co-design in education in the future to new successes. The conditions identified for successful co-design in this book give us some important targets of focus, such as on building collective capabilities for design and on organizational change, in particular. We just need to ask ourselves what infrastructures exist in the contexts where we are working for developing capability and for supporting change and then begin to re-design them together. 


\section{References}

Aguiar, O. G., Mortimer, E., \& Scott, P. (2010). Learning from and responding to students' questions: The authoritative and dialogic tension. Journal of Research in Science Teaching, 47(2), 174-193.

Apple, M. (1982). Education and power. Boston: Routledge.

Bang, M., Medin, D., Washinawatok, K., \& Chapman, S. (2010). Innovations in culturally based science education through partnerships and community. In M. S. Khine \& M. I. Saleh (Eds.), New science of learning: Cognition, computers, and collaboration in education (pp. 569-592). New York: Springer.

Bang, M., \& Vossoughi, S. (2016). Participatory design research and educational justice: Studying learning and relations within social change making. Cognition and Instruction, 34(3), 173-193.

Barajas-López, F., \& Ishimaru, A.M. (in press). "Darles el lugar": A place for nondominant family knowing in educational equity. Urban Education. https://journals.sagepub.com/doi/ full/10.1177/0042085916652179

Björgvinsson, E., Ehn, P., \& Hillgren, P.-A. (2010). Participatory design and democratizing innovation. Paper presented at the Proceedings of the 11th Biennial Participatory Design Conference.

Björgvinsson, E., Ehn, P., \& Hillgren, P.-A. (2012a). Agonistic participatory design: Working with marginalised social movements. CoDesign, 8(2-3), 127-144.

Björgvinsson, E., Ehn, P., \& Hillgren, P.-A. (2012b). Design things and design thinking: Contemporary participatory design challenges. Design Issues, 28(3), 101-117.

Blumenfeld, P., Fishman, B. J., Krajcik, J., Marx, R. W., \& Soloway, E. (2000). Creating usable innovations in systemic reform: Scaling up technology-embedded project-based science in urban schools. Educational Psychologist, 35(3), 149-164.

Booker, A., \& Goldman, S. V. (2016). Participatory design research as a practice for systemic repair: Doing hand-in-hand math research with families. Cognition and Instruction, 34(3), 223-235.

Bowker, G., \& Star, S. L. (1999). Sorting things out: Classification and its consequences. Cambridge, MA: MIT Press.

Bryk, A. S., Gomez, L. M., Grunow, A., \& LeMahieu, P. G. (2015). Learning to improve: How America's schools can get better at getting better. Cambridge, MA: Harvard University Press.

Buzzelli, C., \& Johnston, B. (2001). Authority, power, and morality in classroom discourse. Teaching and Teacher Education, 17(8), 873-884.

Coburn, C. E. (2001). Collective sensemaking about reading: How teachers mediate reading policy in their professional communities. Educational Evaluation and Policy Analysis, 23(2), $145-170$.

Coburn, C. E., \& Penuel, W. R. (2016). Research-practice partnerships in education: Outcomes, dynamics, and open questions. Educational Researcher, 45(1), 48-54.

Coburn, C. E., \& Woulfin, S. L. (2012). Reading coaches and the relationship between policy and practice. Reading Research Quarterly, 47(1), 5-30.

Cohen, D. K., Peurach, D. J., Glazer, J. L., Gates, K., \& Goldin, S. (2013). Improvement by design: The promise of better schools. Chicago: University of Chicago Press.

Crouse, K., Gitomer, D. H., \& Joyce, J. (2016). An analysis of the meaning and use of student learning objectives. In K. K. Hewitt \& A. Amrein-Beardsley (Eds.), Student growth measures in policy and practice (pp. 203-222). New York: Macmillan.

DiSalvo, B., Yip, J., Bonsignore, E., \& DiSalvo, C. (Eds.). (2017). Participatory design for learning: Perspectives from practice and research. New York: Routledge.

Donovan, M. S. (2013). Generating improvement through research and development in educational systems. Science, 340, 317-319.

Ehn, P. (1992). Scandinavian design: On participation and skill. In P. S. Adler \& T. A. Winograd (Eds.), Usability: Turning technologies into tools (pp. 96-132). New York: Oxford University Press. 
Elmore, R. F., \& Burney, D. (1997). Investing in teacher learning: Staff development and instructional improvement in community School District \#2. New York: National Commission on Teaching and America's Future.

Emilson, A., Hillgren, P.-A., \& Seravalli, A. (2014). Designing in the neighborhood: Beyond (and in the shadow of) creative communities. In P. Ehn, E. M. Nilsson, \& R. Topgaard (Eds.), Making futures: Marginal notes on innovation, design, and democracy (pp. 35-62). Cambridge, MA: MIT Press.

Engle, R. A. (2012). The productive disciplinary engagement framework: Origins, key concepts, and developments. In Y. Dai (Ed.), Design research on learning and thinking in educational settings: Enhancing intellectual growth and functioning (pp. 161-200). New York: Routledge.

Esmonde, I., \& Booker, A. N. (2017). Power and privilege in the learning sciences: Critical and sociocultural perspectives. New York: Routledge.

Fishman, B.J., Penuel, W.R., Allen, A.-R., Cheng, B.H., Sabelli, N. (2013). Design-based implementation research: An emerging model for transforming the relationship of research and practice. In B. J. Fishman, W. R. Penuel, A.-R. Allen, \& B. H. Cheng (Eds.), Design-based implementation research. National Society for the Study of Education Yearbook, 112(2), $136-156$.

Fishman, B. J., Penuel, W. R., Hegedus, S., \& Roschelle, J. (2011). What happens when the research ends? Factors related to the sustainability of a technology-infused mathematics curriculum. Journal of Computers in Mathematics and Science Teaching, 30(4), 329-353.

Forman, M. L., Stosich, E. L., \& Bocala, C. (2017). The internal coherence framework: Creating the conditions for continuous improvement in schools. Cambridge, MA: Harvard Educational Press.

Frumin, K. (2018). Researchers and practitioners in partnership: Co-design of a high school biology curriculum. Unpublished doctoral dissertation. Cambridge, MA: Harvard Graduate School of Education.

Gioia, D. A., \& Chittipeddi, K. (1991). Sensemaking and sensegiving in strategic change initiation. Strategic Management Journal, 12(6), 433-448.

Gore, J. M. (1995). On the continuity of power relations in pedagogy. International Studies in Sociology of Education, 5(2), 165-188.

Henrick, E. C., Cobb, P., Penuel, W. R., Jackson, K., \& Clark, T. R. (2017). Assessing researchpractice partnerships: Five dimensions of effectiveness. New York: William T. Grant Foundation.

Hillgren, P.-A., Seravalli, A., \& Emilson, A. (2011). Prototyping and infrastructuring in design for social innovation. CoDesign, 7(3-4), 169-183.

Hopkins, M., \& Spillane, J. P. (2015). Conceptualizing relations between instructional guidance infrastructure (IGI) and teachers' beliefs about mathematics instruction: Regulative, normative, and cultural-cognitive considerations. Journal of Educational Change, 16(4), 431-450.

Institute of Education Sciences, \& National Science Foundation. (2013). Common guidelines for education research and development. Washington, DC: Institute of Education Sciences, \& National Science Foundation.

Ishimaru, A. M., \& Takahashi, S. (2017). Disrupting racialized institutional scripts: Toward parentteacher transformative agency for educational justice. Peabody Journal of Education, 92(3), 343-362.

Jackson, K., \& Cobb, P. (2013). Coordinating professional development across contexts and role group. In M. Evans (Ed.), Teacher education and pedagogy: Theory, policy and practice (pp. 80-99). New York: Cambridge University Press.

Johnson, R., Severance, S., Penuel, W. R., \& Leary, H. A. (2016). Teachers, tasks, and tensions: Lessons from a research-practice partnership. Journal of Mathematics Teacher Education, 19(2), 169-185.

Kirp, D. L. (2013). Improbable scholars: The rebirth of a great American school system and a strategy for America's schools. New York: Oxford University Press. 
Linn, M. C., Kali, Y., Davis, E. A., \& Horwitz, P. (2008). Policies to promote coherence. In Y. Kali, M. C. Linn, \& J. E. Roseman (Eds.), Designing coherent science education (pp. 201-210). New York: Teachers College Press.

Mendoza, E., Kirshner, B., \& Gutiérrez, K. D. (Eds.). (2018). Power, equity and (re)design: Bridging learning and critical theories in learning ecologies for youth. Charlotte, NC: Information Age Publishing.

Michaels, S., O'Connor, C., \& Resnick, L. B. (2008). Deliberative discourse idealized and realized: Accountable talk in the classroom and in civic life. Studies in the Philosophy of Education, 27, 283-297.

Michaels, S., \& O'Connor, M. C. (2011). Talk science primer. Cambridge, MA: TERC.

National Research Council. (2014). Developing assessments for the next generation science standards. Washington, DC: National Academies Press.

Newmann, F. M., Smith, B., Allensworth, E., \& Bryk, A. S. (2001). Instructional program coherence: What it is and why it should guide school improvement policy. Educational Evaluation and Policy Analysis, 23(4), 297-321.

NGSS Lead States. (2013). Next generation science standards: For states, by states. Washington, DC: National Academies Press.

Oyler, C. (1995). Making room for students: Sharing teacher authority in room 104. New York: Teachers College Press.

Pellegrino, J. W. (2013). Proficiency in science: Assessment challenges and opportunities. Science, 340, 320-323.

Penuel, W. R. (2014). Emerging forms of formative intervention research in education. Mind, Culture, and Activity, 21(2), 97-117.

Penuel, W. R. (2015). 'Infrastructuring' as a practice for promoting equity and transformation in design-based implementation research. Paper presented at the International Society for Design and Development in Education (ISDDE) 15, Boulder, CO.

Penuel, W. R. (2017). Building capacity through developing and supporting new curriculum materials in a research-practice partnership. Invited presentation to the Center for Science Teaching and Learning at Northern Arizona University. Boulder, CO: University of Colorado Boulder.

Penuel, W. R., Coburn, C. E., \& Gallagher, D. (2013). Negotiating problems of practice in research-practice partnerships focused on design. In B. J. Fishman, W. R. Penuel, A.-R. Allen, $\&$ B. H. Cheng (Eds.), Design-based implementation research: Theories, methods, and exemplars. National society for the study of education yearbook (pp. 237-255). New York: Teachers College Record.

Penuel, W. R., \& Gallagher, D. (2017). Creating research-practice partnerships in education. Cambridge, MA: Harvard Education Press.

Penuel, W.R., Reiser, B.J., Novak, M., McGill, T., Frumin, K., Van Horne, K. et al. (2018). Using co-design to test and refine a model for three-dimensional science curriculum that connects to students' interests and experiences. Paper presented at the Annual Meeting of the American Educational Research Association, New York, NY.

Penuel, W. R., Roschelle, J., \& Shechtman, N. (2007). Designing formative assessment software with teachers: An analysis of the co-design process. Research and Practice in Technology Enhanced Learning, 2(1), 51-74.

Penuel, W. R., Van Horne, K., Severance, S., Quigley, D., \& Sumner, T. (2016). Students' responses to curricular activities as indicator of coherence in project-based science. In C.-K. Looi, J. L. Polman, U. Cress, \& P. Reimann (Eds.), Proceedings of the 12th international conference of the learning sciences (Vol. 2, pp. 855-858). Singapore: International Society of the Learning Sciences.

Peurach, D. J., \& Neumerski, C. M. (2015). Mixing metaphors: Building infrastructure for large scale school turnaround. Journal of Educational Change, 16(4), 379-420.

Power, M. (2015). How accounting begins: Object formation and the accretion of infrastructure. Accounting, Organizations and Society, 47, 43-55. 
Reiser, B.J., Michaels, S., Moon, J., Bell, T., Dyer, E., Edwards, K.D., et al. (2017). Scaling up three-dimensional science learning through teacher-led study groups across a state. Journal of Teacher Education, 68(3), 280-298.

Reiser, B. J., Novak, M., \& McGill, T. A. W. (2017). Coherence from the students'perspective: Why the vision of the framework for K-12 Science Education requires more than simply "combining three dimensions of science learning". Paper presented at the Board on Science Education Workshop "Instructional Materials for the Next Generation Science Standards, Washington, DC.

Severance, S., Penuel, W. R., Sumner, T., \& Leary, H. (2016). Organizing for teacher agency in curriculum design. Journal of the Learning Sciences, 25(4), 531-564.

Smith, M., \& O'Day, J. A. (1991). Systemic school reform. In S. H. Fuhrman \& B. Malen (Eds.), The politics of curriculum and testing (pp. 233-268). Bristol, PA: Falmer.

Spillane, J. P., Parise, L. M., \& Sherer, J. Z. (2011). Organizational routines as coupling mechanisms: Policy, school administration, and the technical core. American Educational Research Journal, 48(3), 586-619.

Star, S. L. (2010). This is not a boundary object: Reflections on the origin of a concept. Science, Technology, and Human Values, 35, 601-617.

Stephenson, K. (2009). Neither hierarchy nor network: An argument for heterarchy. People and Strategy, 32(1), 4-7.

Woulfin, S. L. (2015). Highway to reform: The coupling of district reading policy and instructional practice. Journal of Educational Change, 16(4), 535-557.

Yeager, D., Bryk, A. S., Muhich, J., Hausman, H., \& Morales, L. (2013). Practical measurement. Stanford, CA: Carnegie Foundation for the Advancement of Teaching.

Open Access This chapter is licensed under the terms of the Creative Commons Attribution 4.0 International License (http://creativecommons.org/licenses/by/4.0/), which permits use, sharing, adaptation, distribution and reproduction in any medium or format, as long as you give appropriate credit to the original author(s) and the source, provide a link to the Creative Commons licence and indicate if changes were made.

The images or other third party material in this chapter are included in the chapter's Creative Commons licence, unless indicated otherwise in a credit line to the material. If material is not included in the chapter's Creative Commons licence and your intended use is not permitted by statutory regulation or exceeds the permitted use, you will need to obtain permission directly from the copyright holder.

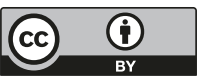

